\title{
Evaluation of Sealing Ability of Biodentine to Root-End Cavities Irrigated either with Maleic Acid or Irritrol Using Glucose Filtration Model
}

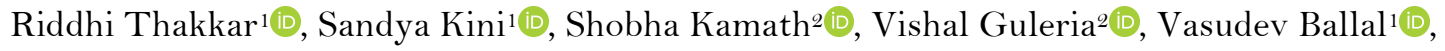 \\ Shashirashmi Acharya ${ }^{1}$
}

\begin{abstract}
${ }^{1}$ Department of Conservative Dentistry and Endodontics, Manipal College of Dental Sciences, Manipal Academy of Higher Education, Manipal, India.

²Department of Biochemistry, Kasturba Medical College, Manipal Academy of Higher Education, Manipal, India.
\end{abstract}

Correspondence: Dr. Sandya Kini, Department of Conservative Dentistry and Endodontics, Manipal College of Dental Sciences, Manipal, 576104, India. E-mail: sandya.kini@manipal.edu

Academic Editor: Catarina Ribeiro Barros de Alencar

Received: 17 June 2020 / Review: 02 September 2020 / Accepted: 18 November 2020

How to cite: Thakkar R, Kini S, Kamath S, Guleria V, Ballal V, Acharya S. Evaluation of sealing ability of biodentine to root-end cavities irrigated either with maleic acid or irritrol using glucose filtration model. Pesqui Bras Odontopediatria Clín Integr. 202 1; 21 :e0136. https://doi.org/10.1590/pboci.2021.055

\begin{abstract}
Objective: To compare the effect of Maleic acid and Irritrol (combination of Chlorhexidine \& Ethylenediaminetetraacetic acid) irrigation on the sealing ability of Biodentine when used as root-end filling material. Material and Methods: Thirty single-rooted human premolars were subjected to standardized root canal instrumentation and were irrigated with 2.5\% Sodium Hypochlorite ( $\mathrm{NaOCl}$ ) after each instrument change. Apical root resections were done by removing $3 \mathrm{~mm}$ of the apex at a $90^{\circ}$ angle to the long axis of the root with a diamond bur. The root end cavity preparation was done using ultrasonic tips at a low power setting under water coolant. They were randomly divided into 3 groups $(n=10)$. Group 1 was irrigated with $7 \%$ Maleic acid, Group 2 was irrigated with Irritrol, and Group 3 was irrigated with $0.9 \%$ Saline (Control). Then, the root end cavities of all the samples were restored with Biodentine and were subjected to leakage analysis using a glucose filtration test. The mean values for each group were calculated and the obtained data was statistically analysed using ANOVA with post-hoc Tukey's test, ANOVA with post-hoc Games-Howell test and repeated measures ANOVA with post-hoc Bonferroni test. Results: The specimens irrigated with Irritrol showed least microleakage as compared to $7 \%$ Maleic acid and $0.9 \%$ Saline. Conclusion: A regimen involving irrigation of the root-end cavity with Irritrol followed by root-end filling with Biodentine can improve the apical seal.
\end{abstract}

Keywords: Endodontics; Root Canal Therapy; Root Canal Filling Materials. 


\section{Introduction}

A well-established approach in the treatment of persistent periapical infection when an orthograde endodontic treatment has failed is apical surgery [1]. To obtain a fluid tight seal of root canal system, root-end filling materials are expected to possess the ability to provide a good seal and other beneficial properties [2]. For a root-end filling material to be ideal, it should be resistant to moisture contamination, antibacterial, nontoxic, non-resorbable, easy to manipulate, radiopaque, cost-effective, easy to adapt, non-cytotoxic and should also lead to regeneration of the surrounding periodontium [3].

Biodentine is a new calcium silicate-based cement. Its biocompatibility has been proved experimentally by Laurent et al. [4]. Based on all its properties, Biodentine has been reported to be a bioactive dentin substitute for repairing root perforations, apexification, and retrograde root filling [5]. In an endodontic treatment, an aseptic technique is employed in which the root canal that is infected should be disinfected.

Intracanal medicaments and irrigants can help in disinfection, thereby enhancing endodontic treatment's success. Although sodium hypochlorite appears to be the most desirable endodontic irrigant, it has been proven that it does not have the ability to remove all of the smear layer and dissolve inorganic dentin particles formed during instrumentation [6-8]. Thus, for effective removal of smear layer, demineralizing agents like Ethylenediaminetetraacetic acid (EDTA), citric acid, etc., have been recommended as adjuvants in root canal therapy [9]. Maleic acid (MA) is a mild organic acid and it has been reported that $7 \%$ maleic acid has been more effective than 17\% EDTA at the apical third of root canal in removing the smear layer of the root canal dentine [10]. Chlorhexidine ( $\mathrm{CHX})$, a bis-biguanide, is a potent antimicrobial agent and its $2 \%$ concentration as an irrigating solution is usually found in the endodontic literature [11]. One of the reasons that Chlorhexidine is popular is its substantivity (i.e., continuous antimicrobial activity) [12]. Canals irrigated with CHX do not negatively affect root fillings' ability to prevent fluid penetration into the root canal system via apical foramen [13].

Irritrol (two-in-one irrigation solution) is a novel endodontic irrigation solution by Essential Dental Systems. It is composed of EDTA, CHX and detergent. Manufacturers claim that Irritrol is a one-step irrigating solution that efficiently removes the smear layer and is less aggressive than conventional irrigants, causing less dentin demineralization [14].

Injudicious use of irrigants will lead to failure in obtaining a fluid tight seal of the root end restoration resulting in microleakage. Till date, no known studies have been carried out that evaluate the sealing ability of Biodentine to root-end cavities when irrigated with either Maleic acid or Irritrol. Hence the purpose of this study is the evaluation of sealing ability of Biodentine to root-end cavities irrigated either with Maleic acid or Irritrol using a glucose filtration test. The null hypothesis tested was: Both MA and Irritrol have no influence on the sealing ability of Biodentine when used as root-end filling material.

\section{Material and Methods}

Ethical Clearance

Ethical clearance was obtained from the Institutional review board (IEC 255/2016).

\section{Experimental Procedures}

Thirty freshly extracted single-rooted human premolars were selected based on inclusion (sound, caries-free, extracted for orthodontic or periodontic reasons, single root canal and completely formed apex) and exclusion criteria (teeth with incompletely formed apex, teeth with resorption, cracks or with endodontic 
restoration). Until the experiment was carried out, the teeth were cleaned and stored in 0.02\% Sodium azide (Sigma Chemical Co., St. Louis, MO). The crowns of all 30 teeth were sectioned with a diamond disc (Horico, Germany) at the CEJ in such a way that the coronal section was perpendicular to the long axis of the root. The working length determination was done using a number $10 \mathrm{~K}$ file (Mani Inc., Utsunomiya, Japan) in the root canal till it was just visible at the apical foramen and then $1 \mathrm{~mm}$ was subtracted from that point. Then, the canal was enlarged to size F3 using rotary protaper files (Dentsply, Maillefer, Ballaigues, Switzerland). Between each instrument change, $5 \mathrm{ml}$ of $2.5 \% \mathrm{NaOCl}$ (KMC Pharmacy, Manipal, India) irrigation was done for 1 minute. Final irrigation was carried out with $5 \mathrm{ml}$ of distilled water for one minute. Paper points (Dentsply, Maillefer, Switzerland) were then used to dry the canal. Irrigation was done with a disposable syringe and 27-gauge monoject needles (Ultradent Products Inc., South Jordan, UT, USA). Apical root preparations were done by removing $3 \mathrm{~mm}$ of apex at a 90-degree angle to the long axis of the tooth with diamond bur (Tungsten Carbide - S.S. White, Lakewood, NJ, USA) under water coolant at high speed. Then, a $3 \mathrm{~mm}$ root end cavity was made in those resected roots using the ultrasonic tip JT-4B, size- $0.3 \mathrm{~mm}$ (B \& L Biotech, Fairfax, VA, USA).

The 30 samples were then randomly divided into 3 groups $(n=10$ each): Group 1: Root end cavity irrigated with 7\% Maleic Acid (KMC Pharmacy, Manipal, India); Group 2: Root end cavity irrigated with Irritrol (Essential Dental Systems, South Hackensack, NJ, USA); and Group 3: Root end cavity irrigated with 0.9\% Normal saline (KMC Pharmacy, Manipal, India).

$5 \mathrm{ml}$ of all irrigating solutions were used for a period of 1 minute. Distilled water was then used for final irrigation for 1 minute in all the groups. Root end cavities were then dried with paper points and were restored with Biodentine. For a coronal matrix, before filling with root end material, a customized endodontic hand plugger was used where Gutta percha point (Dentsply, Maillefer, Ballaigues, Switzerland) of size F3 was cut $6 \mathrm{~mm}$ from the tip and was placed in the root canal $3 \mathrm{~mm}$ short of resected root apex. Wet cotton pellets were used to dry the canal and roots were kept in $100 \%$ humidity at $37^{\circ} \mathrm{C}$ for 24 hours

Microleakage evaluation was done using the glucose filtration test. A modified plastic dropper (both ends of which were cut to accommodate the specimen) was taken. With the help of cyanoacrylate, coronal end of the root was glued to one end of the modified plastic dropper and the other end was connected to a $15 \mathrm{~cm}$ glass tube. Elimination of leakage at both ends was done using sticky wax and cyanoacrylate. Care was taken to ensure that the glue did not cover the root orifice. The tracer used in the study was $1 \mathrm{~mol} / \mathrm{L}$ glucose solution $\left(\mathrm{pH}=7.0\right.$, density $=1.09 \times 103 \mathrm{~g} / \mathrm{L}$, viscosity $=1.18 \times 10^{-3}$ at $\left.37^{\circ} \mathrm{C}\right)$.

About $5 \mathrm{~mL}$ of glucose solution, containing $0.2 \% \mathrm{NaN} 3$, was added to the modified dropper from the plastic tube until the top of the solution became $14 \mathrm{~cm}$ higher than the top of root-end filling, which resulted in creation of hydrostatic pressure of $1.5 \mathrm{kPa}\left(15 \mathrm{~cm} \mathrm{H} \mathrm{H}_{2} \mathrm{O}\right)$. The glucose, which leaked from the canal, was collected in a glass beaker (containing $1 \mathrm{ml}$ of $0.2 \%$ aqueous $\mathrm{NaN}_{3}$ ).

Measurement of Microleakage

A $100 \mu \mathrm{L}$ of solution was drawn from the glass bottle using a micropipette at different time intervals of 24 hours, 4th day and 7 th day. For the maintenance of a constant $1 \mathrm{ml}$ volume, $100 \mu \mathrm{L}$ of fresh $0.2 \% \mathrm{NaN} 3$ was added to the glass bottle reservoir after drawing the sample using a micropipette. Any decrease of volume in the control bottle due to evaporation was maintained by adding a corresponding amount of sterile deionized water to the glass bottle. The sample was then analysed with a Glucose kit in colorimeter at $500 \mathrm{~nm}$ wavelength. Two blinded independent evaluators conducted the colorimetric determination of glucose 
concentration. The results of leakage in all the groups were calculated as $\mathrm{mmol} / \mathrm{L}$ from the respective optical density observed in a colorimeter and the values obtained were then statistically analysed.

Statistical Analysis

The statistical analysis was done using SPSS version 18. A p-value of $<0.05$ was considered to be statistically significant. Inter-group comparison was done with ANOVA with post-hoc Tukey's test and ANOVA with post-hoc Games-Howell test. Intra-group comparison was done with repeated measures ANOVA with post-hoc Bonferroni test.

\section{Results}

There was a significant difference among all three groups $(\mathrm{p}<0.001)$. Post hoc test showed $0.9 \%$ Saline (control) showed maximum leakage at all the time intervals (24 hours, 4th day and 7 th day) $(p<0.001)$ compared to Irritrol and 7\% Maleic acid. On comparing Maleic acid and Irritrol, the former exhibited greater leakage (Table 1). There was also an overall significant difference in the mean results obtained among the three-time intervals. It was seen that with an increase in the number of days, the leakage increased. On the 7 th day, the leakage was maximum compared to the leakage values on the 4 th day and 24 hours.

Table 1. Mean values and standard deviation (SD) of microleakage at each time interval.

\begin{tabular}{cccccc}
\hline \multicolumn{1}{c}{ Groups } & Time & Mean & SD & p-value & Post-hoc Test \\
\hline Maleic Acid & 24 Hours & 1.47 & 0.25 & 0.001 & 4 Days, 7 Days > 24 Hours \\
& 4 Days & 1.73 & 0.2 & & \\
Irritrol & 7 Days & 1.82 & 0.17 & & \\
& 24 Hours & 0.46 & 0.23 & $<0.001$ & 7 Days $>24$ Hours, 4 Days \\
\multirow{2}{*}{ Saline } & 4 Days & 0.61 & 0.2 & & \\
& 7 Days & 0.86 & 0.18 & & \\
& 24 Hours & 2.13 & 0.37 & $<0.001$ & \\
& 4 Days & 2.6 & 0.38 & & \\
\hline
\end{tabular}

Repeated measures ANOVA with Post-hoc Bonferroni Test.

\section{Discussion}

Microleakage that occurs due to improper apical seal in pathologically involved root canals can lead to endodontic failure. The root-end filling material should provide an adequate seal and be compatible with the surrounding periodontium and prevent leakage of microbes and their by-products into the surrounding tissues [15]. Throughout the dental literature, we find a plethora of materials that have been used for retrograde filling. In the present study, Biodentine, a novel material, has been used as a root-end filling material. Biodentine has demonstrated ability to induce odontoblast differentiation and mineralization [16]. The mechanism of action of Biodentine is by the formation of hydrated calcium silicate, which precipitates on the cement particles and forms a matrix [17]. There are multiple advantages of using Biodentine over other calcium silicate-based materials. These include reduced setting time, good mechanical properties, and better handling characteristics [18]. The excellent adaptability of Biodentine to the underlying dentine is dependent mainly on micromechanical adhesion to dentin [17].

In the present study, root-end resections were carried out $3 \mathrm{~mm}$ from the apex and perpendicular to the long axis of tooth as it minimises the number of exposed dentinal tubules. To reduce $98 \%$ of the apical ramifications and $93 \%$ of the lateral canals, $3 \mathrm{~mm}$ of root-end must be eliminated [19]. Traditionally, round 
burs with slow speed handpieces were used to prepare the root-end cavities. However, it possesses many disadvantages like lingual perforation of the root, non-parallel walls, and difficulty accessing the root tip [20]. Hence, ultrasonic tips were used to prepare the root-end cavity. Ultrasonic retro tips have many advantages over the traditional round bur. It has been proven that ultrasonic tips produce a cleaner and a more conservative root end cavity [21].

In the current study, the root canals were not obturated and only leakage through the root-end filling was checked. This allows for the variations due to the obturating materials to be eliminated. Maleic Acid used in our study is a weak organic acid, and has the property of removing the smear layer [22]. 7\% Maleic acid was used in the present study as it has been reported that MA when used in a higher concentration than $7 \%$ caused damage to the intertubular dentin [23]. Another irrigant used in our study was Irritrol, which is a 2-in-1 dual function novel endodontic irrigant. Manufacturers claim that disinfection is accomplished by chlorhexidine $(\mathrm{CHX})$ in it, which allows for a $99.99 \%$ disinfection. Smear Layer removal is accomplished by EDTA, a chelating agent, which removes the inorganic materials, and another proprietary blend of surfactants to remove the organic material.

Since surface demineralization of the dentin and smear layer removal can affect the sealing of the rootend filling materials, 7\% Maleic acid and Irritrol have been compared in this study. Ballal et al. [10] reported that final irrigation with $7 \%$ MA is more efficient than $17 \%$ EDTA in removing the smear layer in the apical third of the root canal system and there was no significant difference in the smear layer removing ability between $7 \%$ Maleic acid and 17\% EDTA in the coronal and middle third of the root canal when used as irrigants for $1 \mathrm{~min}$. In our present study, since the apical third of the root had been resected, the root-end cavity was not exactly at the apical third of the root. The current study demonstrated that $7 \%$ Maleic acid had higher leakage values than the Irritrol group at all time intervals. Hence, the null hypothesis was rejected. It can be justified by the fact that after resecting $3 \mathrm{~mm}$ of root and preparing the root-end cavity of $3 \mathrm{~mm}$, smear layer removal in that region could be more by Irritrol than by $7 \%$ Maleic acid, leading to better sealing ability of Biodentine. Also, the presence of surfactants in Irritrol can enhance its flow rate over a larger area. Hence, this could increase the sealing ability of Biodentine, leading to lesser leakage in that group as compared to $7 \%$ Maleic acid and $0.9 \%$ Saline groups.

Several methods have been employed to assess the sealing ability of root end filling materials, such as dye leakage [24], fluid filtration [25], bacterial penetration [26], radiolabelled isotopes [27] and electromechanical tests [28]. However, they have their own disadvantages, like dye penetration method, although being simple and popular, is not reproducible and can have observer bias [29]. Results might vary with bacterial species used in the bacterial penetration test and it might be problematic to maintain aseptic condition. Also, electrochemical methods and radioisotope labelling might need sophisticated materials and can also pose a radiation hazard [30]. Fluid filtration method is commonly used for microleakage studies. However, it has drawbacks like no standardisation of measurement time, tube diameter containing bubble, pressure, etc., which might influence the result of the study being carried out [25]. In the present study, glucose filtration technique, which was introduced by $\mathrm{Xu}$ et al. [31] for quantitative testing of endodontic leakage, was used as this technique is sensitive, non-destructive and clinically relevant and inexpensive to carry out. The rationale for using glucose as a tracer in this study was its small molecular size and for being a known nutrient for the bacteria [29,32]. Hence, if it could enter the root canal system from oral cavity, the bacteria that might have survived after root canal preparation and obturation could multiply and potentially lead to 
periapical inflammation. Hence, the use of glucose as a tracer in endodontic microleakage studies would be more clinically relevant than using other tracers.

Different time periods for evaluation of microleakage of various root-end restorative materials have been used. It has been seen in various studies that with an increase in time duration, microleakage also increases; hence, in the present study, the leakage was evaluated at 24 hours, 4 days and 7 days [30,33].

\section{Conclusion}

The apical seal of Biodentine retrofill can be enhanced by irrigation with Irritrol.

\section{Authors' Contributions}

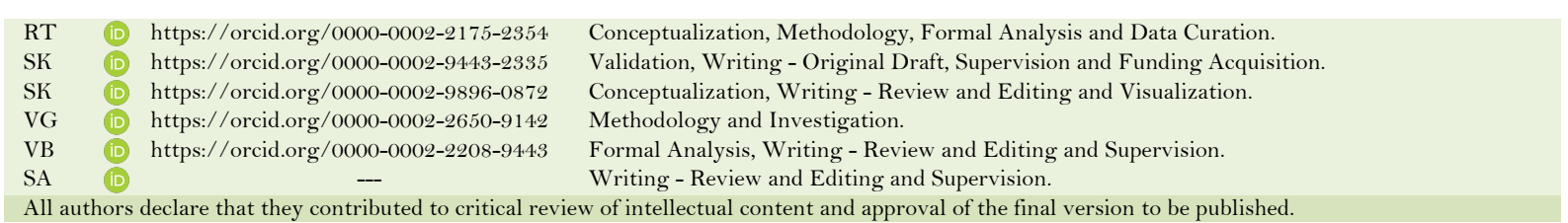

\section{Financial Support}

None.

\section{Conflict of Interest}

The authors declare no conflicts of interest.

\section{Data Availability}

The data used to support the findings of this study can be made available upon request to the corresponding author.

\section{References}

[1] Bergenholtz G, Lekholm U, Milthon R, Heden G, Odesjö B, Engström B. Retreatment of endodontic fillings. Scand J Dent Res 1979; 87(3):217-24 https://doi.org/10.1111/j.1600-0722.1979.tbo0675.x

[2] Torabinejad M, Watson TF, Pitt Ford TR. Sealing ability of a mineral trioxide aggregate when used as a root end filling material. J Endod 1993; 19(12):591-5. https://doi.org/10.1016/S0099-2399(06)80271-2

[3] Gartner AH, Dorn SO. Advances in endodontic surgery. Dent Clin North Am 1992; 36(2):357-78.

[4] Laurent P, Camps J, De Méo M, Déjou J, About I. Induction of specific cell responses to a $\mathrm{Ca}(3) \mathrm{SiO}(5)$-based posterior restorative material. Dent Mater 2008; 24(11):1486-94. https://doi.org/10.1016/j.dental.2008.02.020

[5] Priyalakshmi S, Ranjan M. Review on biodentine - a bioactive dentin substitute. J Dent Med Sci 2014; 13(1):51-7. https://doi.org/10.9790/0853-13131317

[6] Baker NA, Eleazer PD, Averbach RE, Seltzer S. Scanning electron microscopic study of the efficacy of various irrigating solutions. J Endod 1975; 1(4):127-35. https://doi.org/10.1016/Soo99-2399(83)80032-6

[7] Goldman LB, Goldman M, Kronman JH, Lin PS. The efficacy of several irrigating solutions for endodontics: a scanning electron microscopic study. Oral Surg Oral Med Oral Pathol 1981; 52(2):197-204. https://doi.org/10.22037/iej.v2i3.312

[8] Baumgartner JC, Mader CL. A scanning electron microscopic evaluation of four root canal irrigation regimens. J Endod 1987; 13(4):147-57. https://doi.org/10.1016/S0099-2399(87)80132-2

[9] Chockattu SJ, Deepak BS, Goud KM. Comparison of efficiency of ethylenediaminetetraacetic acid, citric acid, and etidronate in the removal of calcium hydroxide intracanal medicament using scanning electron microscopic analysis: An in-vitro study. J Conserv Dent. 2017; 20(1):6-11. https://doi.org/10.4103/0972-0707.209079

[10] Ballal NV, Kandian S, Mala K, Bhat KS, Acharya S. Comparison of the efficacy of maleic acid and ethylenediaminetetraacetic acid in smear layer removal from instrumented human root canal: a scanning electron microscopic study. J Endod 2009; 35(11):1573-6. https://doi.org/10.1016/j.joen.2009.07.021

[11] Gomes BP, Ferraz CC, Vianna ME, Berber VB, Teixeira FB, Souza-Filho FJ. In vitro antimicrobial activity of several concentrations of sodium hypochlorite and chlorhexidine gluconate in the elimination of Enterococcus faecalis. Int Endod J 200 1; 34(6):424-8. https://doi.org/10.1046/j.1365-2591.2001.00410.x 
[12] Khademi AA, Mohammadi Z, Havaee A. Evaluation of the antibacterial substantivity of several intra-canal agents. Aus Endod J 2006; 32(3):1 12-5. https://doi.org/10.1111/j.1747-4477.2006.00033.x

[13] Ferguson DB, Marley JT, Hartwell GR. The effect of chlorhexidine gluconate as an endodontic irrigant on the apical seal: long-term results. J Endod 2003; 29(2):91-4. https://doi.org/10.1097/00004770-200302000-00001.

[14] Essencial Dental Systems (EDS). Products. Endodontic. Irrigation. Irritol. Available from: https://www.edsdental.com/productpdfs/irritrol_profile.pdf]. [Accessed on March 15, 2020].

[15] Valois CR, Costa ED Jr. Influence of the thickness of mineral trioxide aggregate on sealing ability of root-end fillings in vitro. Oral Surg Oral Med Oral Pathol Oral Radiol Endod 2004; 97(1):108-11. https://doi.org/10.1016/s1079-2 104(03)00359-7

[16] Zanini M, Sautier JM, Berdal A, Simon S. Biodentine induces immortalized murine pulp cell differentiation into odontoblast-like cells and stimulates biomineralization. J Endod 2012; 38(9):1220-6. https://doi.org/10.1016/j.joen.2012.04.018

[17] Watson TF, Atmeh AR, Sajini S, Cook RJ, Festy F. Present and future of glass-ionomers and calcium-silicate cements as bioactive materials in dentistry: Biophotonics-based interfacial analyses in health and disease. Dent Mater 2014; 30(1):50-61. https://doi.org/10.1016/j.dental.2013.08.202

[18] Santos AD, Moraes JC, Araújo EB, Yukimitu K, Valério Filho WV. Physico-chemical properties of MTA and a novel experimental cement. Int Endod J 2005; 38(7):443-7. https://doi.org/10.1111/j.1365-2591.2005.00963.x

[19] Mjör IA, Smith MR, Ferrari M, Mannocci F. The structure of dentine in the apical region of human teeth. Int Endod J 2001; 34(5):346-53. https://doi.org/10.1046/j.1365-2591.2001.00393.x

[20] Carr GB. Ultrasonic root end preparation. Dent Clin North Am 1997; 41(3):541-54.

[21] Khabbaz MG, Kerezoudis NP, Aroni E, Tsatsas V. Evaluation of different methods for the root-end cavity preparation. Oral Surg Oral Med Oral Pathol Oral Radiol Endod 2004; 98(2):237-42. https://doi.org/10.1016/j.tripleo.2004.02.062

[22] Ballal NV, Mala K, Bhat KS. Evaluation of decalcifying effect of maleic acid and EDTA on root canal dentin using energy dispersive spectrometer. Oral Surg Oral Med Oral Pathol Oral Radiol Endod 2011; 112(2):78-84. https://doi.org/10.1016/j.tripleo.2011.01.034

[23] Prabhu SG, Rahim N, Bhat KS, Mathew J. Comparison of removal of endodontic smear layer using sodium hypochlorite, EDTA and different concentrations of maleic acid - A SEM study. Endodontology 2003; 15(1):20-5.

[24] Starkey DL, Anderson RW, Pashley DH. An evaluation of the effect of methylene blue dye pH on apical leakage. J Endod 1993; 19(9):435-9. https://doi.org/10.1016/s0099-2399(06)80529-7

[25] Pommel L, Camps J. Effects of pressure and measurement time on the fluid filtration method in endodontics. J Endod 2001; 27(4):256-8. https://doi.org/10.1097/00004770-200104000-00003

[26] Kersten HW, Moorer WR. Particles and molecules in endodontic leakage. Int Endod J 1989; 22(3):118-24. https://doi.org/10.1111/j.1365-2591.1989.tboo909.x

[27] Haïkel Y, Wittenmeyer W, Bateman G, Bentaleb A, Allemann C. A new method for the quantitative analysis of endodontic microleakage. J Endod 1999; 25(3):172-7. https://doi.org/10.1016/s0099-2399(99)80136-8

[28] Von Fraunhofer JA, Fagundes DK, McDonald NJ, Dumsha TC. The effect of root canal preparation on microleakage within endodontically treated teeth: an in vitro study. Int Endod J 2000; 33(4):355-60. https://doi.org/10.1046/j.1365-2591.2000.00318.x

[29] Wu MK, Wesselink PR. Endodontic leakage studies reconsidered. Part I. Methodology, application and relevance. Int Endod J 1993; 26(1):37-43. https://doi.org/10.1111/j.1365-2591.1993.tbo0540.x

[30] Chhaparwal S, Ballal NV, Menezes ND, Kamath SU. Effect of chelating agents on sealing ability of Biodentine and mineral trioxide aggregate. Saudi Endod J 2017; 7(1):16-22. https://doi.org/10.4103/1658-5984.197983

[31] Xu Q, Fan MW, Fan B, Cheung GS, Hu HL. A new quantitative method using glucose for analysis of endodontic leakage. Oral Surg Oral Med Oral Pathol Oral Radiol Endod 2005; 99(1):107-11. https://doi.org/10.1016/j.tripleo.2004.06.006

[32] Friedman S. Retrograde approaches in endodontic therapy. Endod Dent Traumatol 1991; 7(3):97-107. https://doi.org/10.1111/j.1600-9657.1991.tbo0192.x

[33] Mathew LA, Kini S, Acharya SR, Kamath S, Menezes ND, Rao S. A comparative evaluation of the microleakage of blood-contaminated mineral trioxide aggregate and Biodentine as root-end filling materials: an in vitro study. J Interdiscip Dentistry 2016; 6(1):19-24. https://doi.org/10.4103/2229-5194.188159 